\title{
Effective Lavage Volume of Diluted Surfactant Improves the Outcome of Meconium Aspiration Syndrome in Newborn Piglets
}

\author{
MEI-JY JENG, WEN-JUE SOONG, AND YU-SHENG LEE
}

Institute of Emergency and Critical Care Medicine [M.-J.J., Y.-S.L.], Department of Pediatrics [M.-J.J., W.-J.S., Y.-S.L], National Yang-Ming University, Taipei 11221, Taiwan, R.O.C.; Department of Pediatrics [M.-J.J., W.-J.S., Y.-S.L], Taipei Veterans General Hospital, Taipei 11217, Taiwan, R.O.C

\begin{abstract}
Meconium aspiration syndrome (MAS) is one of the top causes of severe respiratory failure in neonates. This study was designed to investigate the effective volume of therapeutic bronchoalveolar lavage (BAL) with diluted surfactant in the treatment of MAS in newborn piglets. Human meconium was instilled in 24 piglets to induce MAS, and the piglets were randomly divided into four groups: 1) control, no lavage; 2) lavage-10, BAL with diluted surfactant (5 $\mathrm{mg} / \mathrm{mL}$, Survanta) $10 \mathrm{~mL} / \mathrm{kg}$ in two aliquots; 3) lavage- $20,20 \mathrm{~mL} / \mathrm{kg}$ in two aliquots; 4) lavage-30, $30 \mathrm{~mL} / \mathrm{kg}$ in two aliquots. Cardiopulmonary parameters were monitored, and the lung tissue was histologically examined after experiments. The changes in oxygenation and lung compliance of lavage-20 and lavage-30 groups were significantly better than control and lavage-10 groups $(p<0.05)$, but there was no significant difference between lavage-20 and lavage-30 groups. The lung injury scores were significantly lower in the dependent site of lavage-20 and lavage-30 groups than the other two groups. In conclusion, using $20 \mathrm{~mL} / \mathrm{kg}$ diluted surfactant in two aliquots to perform therapeutic BAL was as effective as $30 \mathrm{~mL} / \mathrm{kg}$ in improving the pathophysiological outcomes in MAS and may warrant consideration clinically in treating MAS. (Pediatr Res 66: 107-112, 2009)
\end{abstract}

$\mathrm{M}$ econium aspiration syndrome (MAS) is one of the top causes of severe respiratory failure in neonates. Despite improvement in immediate resuscitation at birth and the use of assisted ventilation, respiratory distress caused by aspirated meconium is difficult to manage. Even with innovative respiratory care, some neonates with severe MAS may become candidates for extracorporeal membrane oxygenation and high rates of mortality may occur (1-3).

The mechanisms in pathogenesis of MAS typically includes local obstruction of the airway by meconium debris, with associated impairment of gas diffusion, patchy atelectasis, pulmonary vascular hypertension, pulmonary inflammation, chemical pneumonitis, and surfactant inactivity (4-10). Bolus surfactant administration has been tested for the treatment of MAS previously, but no significant reduction in mortality and other morbidities was obtained (11-14).

Received October 28, 2008; accepted February 17, 2009.

Correspondence: Mei-Jy Jeng, M.D., Ph.D., Institute of Emergency and Critical Care Medicine, School of Medicine, National Yang-Ming University, Taipei 11221, Taiwan, R.O.C.; e-mail: mjjeng@vghtpe.gov.tw

Supported by grants NSC95-2314-B-010-091-MY3 from the National Science Council, Taiwan and grant VGH95C1-078 from Taipei Veterans General Hospital, Taipei, Taiwan.

Presented at the Pediatric Academic Societies and Asian Society for Pediatric Research 2008 Joint Meeting in Honolulu, Hawaii
Effective meconium removal without inactivating or washing out surfactant is a potential additional treatment for treating MAS. Theoretically, the concept of therapeutic bronchoalveolar lavage (BAL) involves dilution and removal of the meconium from the airspaces. Intervention to treat progressive MAS using BAL with saline has not proved to be clinically useful $(15,16)$ and may even be detrimental as the volume of saline can further impede gas exchange and worsen lung mechanics. Some authors have tried to use bolus surfactant given after saline lavage $(15,17-20)$, but the surfactant distribution was not uniformly obtained in the same manner as when using surfactant lavage $(21,22)$.

Recently, technique of therapeutic BAL with diluted exogenous surfactant has been tried and shown some promising benefits in improving pathophysiological responses, increasing meconium removal amount, lowering ventilation duration, and decreasing the severity of illness $(12,23-40)$. However, the techniques of therapeutic BAL are quite different among reported animal (Table 1) $(23,25-27,30,32-35,40)$ and neonatal studies (Table 2) $(24,28,29,31,36-39)$. The biggest difference was the lavage volume of each aliquot (range: $2 \mathrm{~mL} /$ aliquot to $20 \mathrm{~mL} /$ $\mathrm{kg} /$ aliquot) and lavage frequencies (range, 2-30 aliquots), thus resulting in a large difference in total lavage volume (range, $9 \mathrm{~mL}$ totally to $80 \mathrm{~mL} / \mathrm{kg}$ ) (Tables 1 and 2). Therefore, further studies to elucidate the controversies in the BAL technique and whether to BAL are crucial for neonatal applications.

We hypothesized that using an effective lavage volume of diluted surfactant may improve the pathophysiological outcome of MAS. This study was designed to test this hypothesis in an experimental model of newborn piglets with MAS (25).

\section{MATERIALS AND METHODS}

All animals were managed according to the National Institutes of Health guidelines for the care of animal subjects. All procedures were approved by the local Institutional Review Board.

Subjects. Neonatal piglets less than 2 wk of age were anesthetized with intramuscularly administered atropine $(0.1 \mathrm{mg} / \mathrm{dose})$ and ketamine $(25 \mathrm{mg} /$ $\mathrm{kg} /$ dose) before surgical procedures. All animals were placed in a supine position and given a s.c. injection of lidocaine hydrochloride $(2 \%)$ for local anesthesia. After placing an uncuffed endotracheal tube (3.5 mm ID, Portex tracheal tube, SIMS Portex, Hythe, Kent, UK) via a tracheotomy, controlled

Abbreviations: BAL, bronchoalveolar lavage; Crs, compliance of the respiratory system; MAS, meconium aspiration syndrome; $\mathbf{P a C O} \mathbf{O}_{2}$, arterial partial pressure of carbon dioxide; $\mathbf{P a O}_{2}$, arterial partial pressure of oxygen; $\mathbf{S p O}_{2}$, peripheral capillary oxygen saturation 
Table 1. Reported volumes of therapeutic surfactant lavage in meconium aspiration syndrome with animal models (1992-2008)

\begin{tabular}{|c|c|c|c|c|c|c|}
\hline Surfactant & Concentration $(\mathrm{mg} / \mathrm{mL})$ & Volume (per aliquot) & Aliquots & Volume (totally) & Animal model (subjects number) & Reference \\
\hline Curosurf & 10 & $3.3 \mathrm{~mL} / \mathrm{kg}$ & 3 & $10 \mathrm{~mL} / \mathrm{kg}$ & Rabbits (6) & 23 \\
\hline Survanta & 5 & $5 \mathrm{~mL} / \mathrm{kg}$ & 4 & $20 \mathrm{~mL} / \mathrm{kg}$ & Piglets (5) & 25 \\
\hline Surfacten & 6 & $2 \mathrm{~mL} / \mathrm{kg}$ & 4 & $8 \mathrm{~mL} / \mathrm{kg}$ & Rabbits (7) & 32 \\
\hline \multirow[t]{2}{*}{ Survanta } & 2.5 & $15 \mathrm{~mL} / \mathrm{kg}$ & 2 & $30 \mathrm{~mL} / \mathrm{kg}$ & Piglets (8) & 30 \\
\hline & & $3 \mathrm{~mL}$ & $10 / \mathrm{kg}^{*}$ & $30 \mathrm{~mL} / \mathrm{kg}$ & Piglets (8) & \\
\hline Survanta & 5 & $2.5 \mathrm{~mL} / \mathrm{kg}$ & 4 & $10 \mathrm{~mL} / \mathrm{kg}$ & Piglets (6) & 33 \\
\hline Surfactant-TA & $12 \mathrm{mg} / \mathrm{kg} / \mathrm{aliquot}$ & $2.5 \mathrm{~mL}$ & 4 & $10 \mathrm{~mL}$ & Piglets (6) & 34 \\
\hline Surfactant-TA & $2.5,5,10$ & $3.3 \mathrm{~mL} / \mathrm{kg}$ & 3 & $10 \mathrm{~mL} / \mathrm{kg}$ & Rabbits (18) & 27 \\
\hline $\mathrm{KL}_{4}$-surfactant & 2,15 & $20 \mathrm{~mL} / \mathrm{kg}$ & 4 & $80 \mathrm{~mL} / \mathrm{kg}$ & Rabbit (5) & $40 \dagger$ \\
\hline Surfactant-TA & 5 & $2.5 \mathrm{~mL} / \mathrm{kg}$ & 4 & $10 \mathrm{~mL} / \mathrm{kg}$ & Rabbits (5) & 35 \\
\hline Survanta & 25 & $5 \mathrm{~mL} / \mathrm{kg}$ & 2 & $10 \mathrm{~mL} / \mathrm{kg}$ & Piglets (7) & 26 \\
\hline
\end{tabular}

Curosurf (product of Chiesi Farmaceutici, S.p.A, Parma, Italy, and manufactured for Dey laboratories, Napa, CA); Surfacten (product of Mitsubishi Pharma,

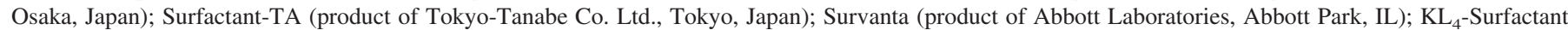
(product of Johnson and Johnson Company, Raritan, NJ).

* The total lavage volume was $30 \mathrm{~mL} / \mathrm{kg}$ and each aliquot was $3 \mathrm{~mL}$, so the total aliquots was 10 aliquots/kg ( 30 aliquots in an 3-kg animal).

$\dagger$ For each aliquot, the volume of $20 \mathrm{~mL} / \mathrm{kg}$ was divided into two equal portions, one half into the right lung, and the second half into the left lung. The surfactant concentrations were $2 \mathrm{mg} / \mathrm{mL}$ at the first 3 lavages, and $15 \mathrm{mg} / \mathrm{mL}$ at the 4 th lavage.

Table 2. Reported volumes of therapeutic surfactant lavage in neonates with meconium aspiration syndrome (1999-2008)

\begin{tabular}{|c|c|c|c|c|c|c|}
\hline Surfactant & Concentration $(\mathrm{mg} / \mathrm{mL})$ & Volume (per aliquot) & Aliquots & Volume (totally) & Subjects number & Reference \\
\hline Survanta & 5 & $15 \mathrm{~mL} / \mathrm{kg}$ & 2 & $30 \mathrm{~mL} / \mathrm{kg}$ & 3 & 31 \\
\hline Survanta & 5 & $3-15 \mathrm{~mL} / \mathrm{kg}$ & $2-3$ & $9-30 \mathrm{~mL} / \mathrm{kg}$ & 8 & $29 *$ \\
\hline \multirow[t]{2}{*}{ Survanta } & 10 & $2 \mathrm{~mL}$ & 10 & $20 \mathrm{~mL}$ & 11 & 36 \\
\hline & 5 & $2 \mathrm{~mL}$ & 20 & $40 \mathrm{~mL}$ & 9 & \\
\hline Curosurf & 5.3 & $2.5 \mathrm{~mL}$ & $6 / \mathrm{kg}$ & $15 \mathrm{~mL} / \mathrm{kg}$ & 8 & 37 \\
\hline Curosurf & 5 & $7.5 \mathrm{~mL} / \mathrm{kg}$ & 2 & $15 \mathrm{~mL} / \mathrm{kg}$ & 1 & 38 \\
\hline Survanta & 5 & $3.75 \mathrm{~mL} / \mathrm{kg}$ & 4 & $15 \mathrm{~mL} / \mathrm{kg}$ & 18 & 39 \\
\hline Surfaxin & 2.5 , then 10 & $8 \mathrm{~mL} / \mathrm{kg}$ & 6 & $48 \mathrm{~mL} / \mathrm{kg}$ & 15 & $24 \dagger$ \\
\hline Survanta & 5 & $2 \mathrm{~mL}$ & $7.5 / \mathrm{kg}$ & $15 \mathrm{~mL} / \mathrm{kg}$ & 6 & 28 \\
\hline
\end{tabular}

Curosurf (product of Chiesi Farmaceutici, S.p.A, Parma, Italy, and manufactured for Dey laboratories, Napa, CA); Surfaxin (product of Discovery Laboratories, Inc, Warrington, PA); Survanta (product of Abbott Laboratories, Abbott Park, IL).

* 9-15 mL/kg in 2-3 aliquots were done in four cases, and $20-30 \mathrm{~mL} / \mathrm{kg}$ in two aliquots in another four cases

$\dagger$ The concentration of first four aliquots was $2.5 \mathrm{mg} / \mathrm{mL}$, and there were other seven cases in control group.

mechanical ventilation was established using a volume-controlled animal ventilator (Model 683, Harvard, South Natick, MA). Tidal volume $\left(V_{\mathrm{T}}\right)$ was set at $10 \mathrm{~mL} / \mathrm{kg}$, the ventilator rate at $30 \mathrm{breaths} / \mathrm{min}$, the I:E ratio at $1: 1$, positive end-expiratory pressure (PEEP) at $5 \mathrm{~cm} \mathrm{H}_{2} \mathrm{O}$, and the fractional concentration of inspired oxygen $\left(\mathrm{FiO}_{2}\right)$ at 1.0 . These ventilator settings were kept constant throughout the experiments, except the ventilator rate was increased by $2-5$ breaths/min when the blood gas analysis showed arterial $\mathrm{PCO}_{2}\left(\mathrm{PaCO}_{2}\right)$ higher than $50 \mathrm{~mm} \mathrm{Hg}$ and $\mathrm{pH}$ less than 7.25. A $3.5-\mathrm{Fr}$ umbilical vessel catheter (Argyle, Sherwood Medical Corp., St. Louis, MO) was placed in the right femoral vein for medication and anesthesia. After the induction of anesthesia, a solution of $0.33 \%$ saline in 5\% dextrose was infused i.v. at a rate of $5 \mathrm{~mL} / \mathrm{kg} / \mathrm{h}$. Animals were then paralyzed with i.v. pancuronium bromide $(0.2 \mathrm{mg} / \mathrm{kg})$, sedated with midazolam $(0.5 \mathrm{mg} / \mathrm{kg})$, and maintained with a continuous infusion of ketamine $(5 \mathrm{mg} / \mathrm{kg} / \mathrm{h})$, midazolam $(0.5 \mathrm{mg} / \mathrm{kg} /$ $\mathrm{h}$ ), and pancuronium bromide $(0.2 \mathrm{mg} / \mathrm{kg} / \mathrm{h})$. A $3.5-\mathrm{Fr}$ umbilical vessel catheter (Argyle, Sherwood Medical Corp., St. Louis, MO) was placed in the right femoral artery for continuous recording of arterial blood pressure and for blood sampling. Body temperature was maintained at $38-39^{\circ} \mathrm{C}$ throughout the experiment by a servo-controlled heating blanket.

Physiologic monitoring. Throughout the experiment, the electrocardiograph, mean arterial blood pressure (MBP), peripheral capillary oxygen saturation $\left(\mathrm{SpO}_{2}\right)$, and anal temperature were continuously monitored (HP M1205A OmniCare Model 24/24C; Hewlett-Packard Company, Palo Alto, CA). Respiratory flow was measured with a Fleisch No 3 heated capillary tube pneumotachograph (Richmond, VA) coupled with a differential pressure transducer (MP-45-16; Validyne, Northridge, CA). The pressure transducers were calibrated using a water manometer. All signals for respiratory flow and airway pressure were recorded with a data acquisition system (PowerLab 16/30; ADInstruments Pty LTD, Bella Vista, NSW, Australia). The flow signal was integrated to give $V_{\mathrm{T}}$, and compliance of the respiratory system (Crs) was measured on a breath-by-breath basis with an on-line computer system equipped with an analog/digital converter (DA100C; BIOPAC System, Inc., Goleta, CA) and appropriate software (Chart \& Scope; ADInstruments Pty LTD, Bella Vista, NSW, Australia). Arterial blood samples for blood gas analysis (STAT 3; NOVA Biomedical, Waltham, MA) were taken every $30 \mathrm{~min}$ until the end of experiments.

Induction of meconium aspiration injury. Meconium obtained from healthy human infants less than 24-h-old was pooled, homogenized, diluted with $0.9 \%$ saline to a $20 \%$ (by weight) slurry, and frozen $\left(-20^{\circ} \mathrm{C}\right)$ until use.

After baseline measurements, the animals were given 3-5 aliquots of $1 \mathrm{~mL} / \mathrm{kg}$ $20 \%$ meconium slurry via the endotracheal tube using an 8-Fr feeding tube as an introducing catheter. The goal was to reduce arterial $\mathrm{Po}_{2}\left(\mathrm{PaO}_{2}\right)$ to less than $100 \mathrm{~mm}$ $\mathrm{Hg}\left(13.3 \mathrm{kPa}\right.$ ) at $\mathrm{FiO}_{2} 1.0$ and $\mathrm{Crs}$ to lower than $2 / 3$ of the baseline value (25).

Experimental protocol. After the induction of meconium aspiration injury, a period of $20 \mathrm{~min}$ was allowed for stabilization before postinjury physiologic data were measured. A total of 24 newborn piglets received meconium instillation and were randomly assigned to one of four study groups. They were as follows: 1) control group $(n=6)$ : animals received tracheal suctioning until the suctioned fluid was clear; 2) lavage-10 group $(n=6): 10 \mathrm{~mL} / \mathrm{kg}$ diluted surfactant ( $5 \mathrm{mg} / \mathrm{mL}$, Survanta; Abbott Laboratories, Abbott Park, IL) in two aliquots was used for BAL; 3 ) lavage- 20 group $(n=6): 20 \mathrm{~mL} / \mathrm{kg}$ diluted surfactant in two aliquots was used for BAL; and 4) lavage-30 group $(n=6): 30 \mathrm{~mL} / \mathrm{kg}$ diluted surfactant in two aliquots was used for BAL. Physiologic post-therapy data were measured at 30-min intervals for a total of $4 \mathrm{~h}$. The concentration of surfactant was chosen to be $5 \mathrm{mg} / \mathrm{mL}$ because that was the most common applied concentration in human and animal studies, and there was no evidence to show better outcome with a higher or lower concentration (Table 1 and 2). Two aliquots were chosen to minimize the frequencies of possible oxygenation desaturation induced by $\operatorname{BAL}(26,29-31,38)$.

During BAL, the lavage fluid was instilled via a feeding tube into the endotracheal tube. After positive pressure ventilation for $10 \mathrm{~s}$, the fluid was suctioned out using a suction catheter (8.0-Fr) connected to a mucus specimen trap (Bard Mucous Specimen Trap $80 \mathrm{~mL}$; C.R. Bard, Inc., Covington, GA) to collect the return fluid (29-31). The second lavage would be performed at least 5 min after the first lavage, and the $\mathrm{SpO}_{2}$ should be higher than $80 \%$. Further suctioning was performed if there was evidence of residual meconium-stained fluid when the oxygen saturation returned to higher than $80 \%$. 
At the end of the experiments, the animals were euthanized with a high dose of $15 \%$ potassium chloride. With the PEEP kept at $5 \mathrm{~cm} \mathrm{H}_{2} \mathrm{O}$, the chest was opened and the lungs were inspected to assess gross morphology. Two blocks of the right lung (nondependent site of the middle lobe and dependent site at the superior segment of the lower lobe, around $1 \mathrm{~cm}^{3}$ ) were obtained and fixed by immersion in $10 \%$ formaldehyde solution for more than $24 \mathrm{~h}$. Tissue specimens were embedded in paraffin and were cut into sections, which were subsequently stained with hematoxylin and eosin. Sections were examined in a blinded fashion using light microscopy (Olympus AX-80; Yuanyu Industry CO, LTD, Taipei, Taiwan). The histology was scored using a quantitative scoring system by an investigator blinded to the study group. Injury variables scored were alveolar and interstitial inflammation, alveolar and interstitial hemorrhage, atelectasis, and necrosis $(41,42)$. The severity of injury was graded according to the following scales: no injury $=0$; injury to $25 \%$ of the field $=1$; injury to $50 \%$ of the field $=$ 2 ; injury to $75 \%$ of the field $=3$; and diffuse injury $=4$.

Data analysis. Values were presented as the mean \pm SEM for parametric data or median (range) for nonparametric data. Data analysis was performed using SigmaStat 3.1 (Systat Software, Inc., Point Richmond, CA). A paired $t$ test and Wilcoxon Signed Ranks test were used to compare data in the same group when appropriate. One-way ANOVA and KruskalWallis test were used to compare data among the different groups when appropriate. Two-way repeated measure ANOVA was used to analyze the serial data over the experimental period of time among different groups. A post hoc Student-Newman-Keuls test was performed for multiple pairwise comparisons if $p<0.05$. Significance was accepted at the $p<0.05$ level.

\section{RESULTS}

Characteristics of study animals and effects of meconiumaspirated lung injury. Mean body weight $(1.7 \pm 0.1,1.8 \pm$ $0.1 .1 .6 \pm 0.1$, and $1.6 \pm 0.1 \mathrm{~kg}$, respectively) and age (7 \pm $0,10 \pm 1,9 \pm 1$, and $7 \pm 1$-d-old, respectively) did not vary significantly among the four study groups (Table 3 ). Before meconium instillation, cardiopulmonary profiles did not vary among the groups. There was no significant difference in the

Table 3. Characteristics of study animals at baseline and postinjured, pretreatment stage

\begin{tabular}{|c|c|c|c|c|c|c|c|c|}
\hline Group & $\mathrm{pH}$ & $\begin{array}{c}\mathrm{PaCO}_{2} \\
(\mathrm{~mm} \mathrm{Hg}) \\
\end{array}$ & $\begin{array}{c}\mathrm{PaO}_{2} \\
(\mathrm{~mm} \mathrm{Hg}) \\
\end{array}$ & $\begin{array}{c}\mathrm{A}-\mathrm{aDO}{ }_{2} \\
(\mathrm{~mm} \mathrm{Hg})\end{array}$ & $\begin{array}{c}\text { Peak inspiratory } \\
\text { pressure }\left(\mathrm{cm} \mathrm{H}_{2} \mathrm{O}\right)\end{array}$ & $\begin{array}{c}\mathrm{Crs} \\
\left(\mathrm{mL} / \mathrm{cm} \mathrm{H}_{2} \mathrm{O} / \mathrm{kg}\right)\end{array}$ & $\begin{array}{c}\text { Heart rate } \\
\text { (beats/min) }\end{array}$ & $\begin{array}{c}\text { Mean blood } \\
\text { pressure }(\mathrm{mm} \mathrm{Hg})\end{array}$ \\
\hline \multicolumn{9}{|l|}{ Baseline } \\
\hline Control & $7.42 \pm 0.03$ & $38 \pm 3$ & $443 \pm 26$ & $223 \pm 24$ & $13 \pm 1$ & $0.91 \pm 0.02$ & $186 \pm 21$ & $87 \pm 5$ \\
\hline Lavage-10 & $7.42 \pm 0.03$ & $41 \pm 3$ & $464 \pm 37$ & $198 \pm 34$ & $15 \pm 1$ & $0.79 \pm 0.08$ & $172 \pm 19$ & $86 \pm 6$ \\
\hline Lavage-20 & $7.47 \pm 0.02$ & $35 \pm 1$ & $467 \pm 7$ & $202 \pm 8$ & $16 \pm 1$ & $0.80 \pm 0.04$ & $152 \pm 16$ & $83 \pm 3$ \\
\hline Lavage-30 & $7.42 \pm 0.04$ & $33 \pm 3$ & $436 \pm 28$ & $173 \pm 11$ & $13 \pm 3$ & $0.78 \pm 0.04$ & $185 \pm 26$ & $82 \pm 6$ \\
\hline \multicolumn{9}{|c|}{ Postinjury, pretreatment } \\
\hline Control & $7.33 \pm 0.04 *$ & $61 \pm 5^{*}$ & $67 \pm 6^{*}$ & $581 \pm 7 *$ & $23 \pm 2 *$ & $0.43 \pm 0.01 *$ & $190 \pm 24$ & $84 \pm 6$ \\
\hline Lavage-10 & $7.32 \pm 0.04 *$ & $53 \pm 4^{*}$ & $65 \pm 5^{*}$ & $582 \pm 4^{*}$ & $27 \pm 1 *$ & $0.39 \pm 0.02 *$ & $202 \pm 24$ & $95 \pm 4$ \\
\hline Lavage-20 & $7.37 \pm 0.02 *$ & $46 \pm 3^{*}$ & $74 \pm 7 *$ & $582 \pm 6^{*}$ & $26 \pm 1 *$ & $0.40 \pm 0.02 *$ & $157 \pm 21$ & $93 \pm 5$ \\
\hline Lavage-30 & $7.34 \pm 0.01 *$ & $54 \pm 4^{*}$ & $77 \pm 8^{*}$ & $569 \pm 10^{*}$ & $22 \pm 4^{*}$ & $0.42 \pm 0.02 *$ & $195 \pm 22$ & $89 \pm 4$ \\
\hline
\end{tabular}

Control, no lavage; Lavage-10, lavage with $10 \mathrm{~mL}$ diluted surfactant; Lavage-20, lavage with $20 \mathrm{~mL}$ diluted surfactant; Lavage-30, lavage with $30 \mathrm{~mL}$ diluted surfactant. $* p<0.05 v s$. the corresponding preinjury data of the same group. Data are expressed as the mean \pm SEM.
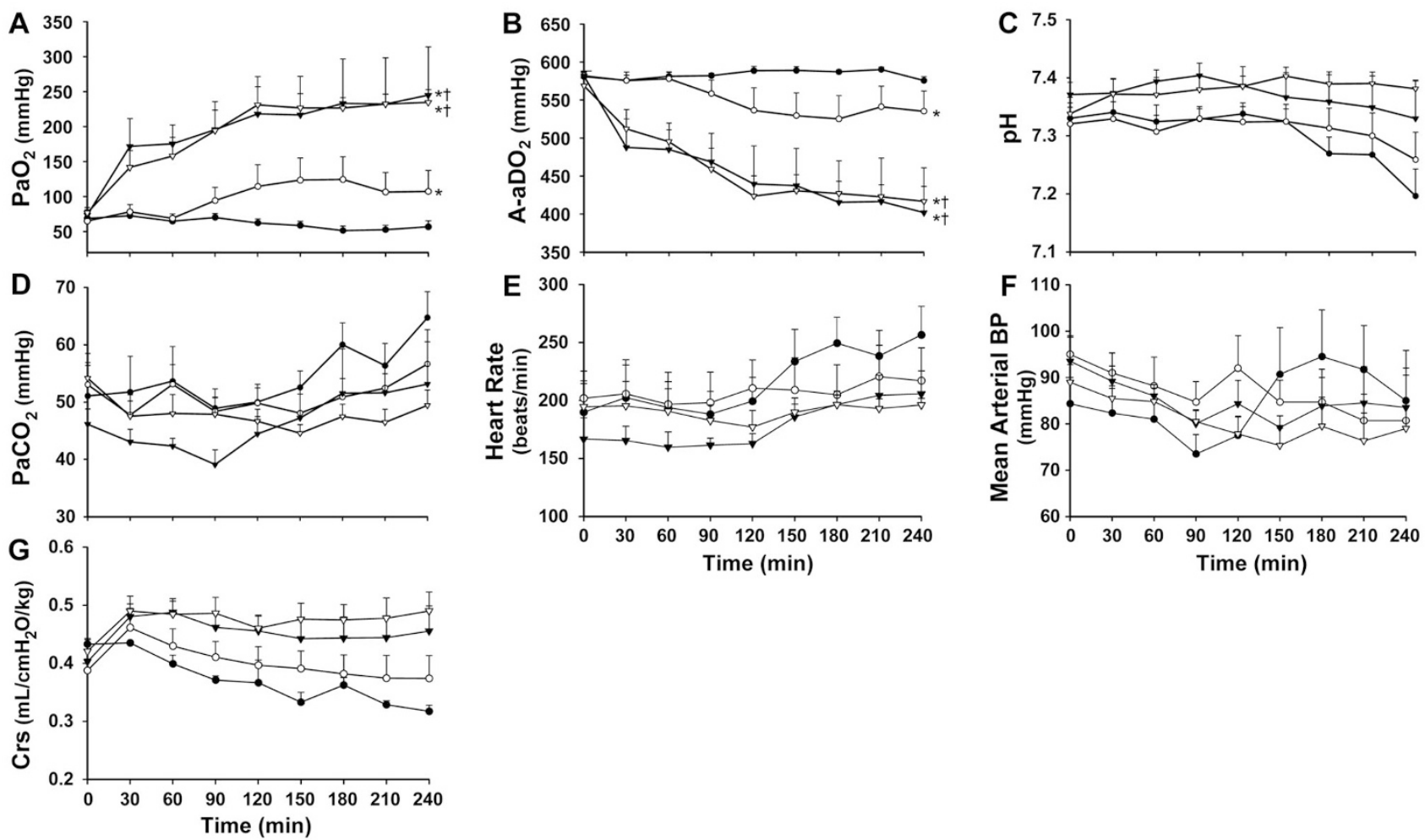

Figure 1. Changes of cardiopulmonary profiles during the 4-h experiments (mean $\pm \mathrm{SEM}$ ). $A$, changes in $\mathrm{PaO}_{2} ; B$, changes in alveolar-arterial oxygen difference $\left(\mathrm{A}-\mathrm{aDO}_{2}\right) ; C$, changes in $\mathrm{pH} ; D$, changes in $\mathrm{PaCO}_{2} ; E$, changes in heart rate; $F$, changes in blood pressure; $G$, changes in Crs. Control $(\bullet)$ : no lavage $(n=6)$; lavage- 10 (○): bronchoalveolar lavage (BAL) with $10 \mathrm{~mL} / \mathrm{kg}$ diluted surfactant $(n=6)$; lavage-20 ( $\mathbf{\nabla})$ : BAL with $20 \mathrm{~mL} / \mathrm{kg}$ diluted surfactant $(n=6)$; lavage-30 ( $\nabla)$ : BAL with $30 \mathrm{~mL} / \mathrm{kg}$ diluted surfactant $(n=6)$. (*) Two way repeated measure ANOVA $p<0.05 v s$. control group; $(\dagger)$ Two way repeated measure ANOVA $p<0.05 v s$. lavage-10 group. 
instilled amount of meconium among the groups $(3.8 \pm 0.7$, $3.5 \pm 0.2,3.8 \pm 0.3,3.2 \pm 0.2 \mathrm{~mL} / \mathrm{kg}$, respectively). Immediately after induction of meconium aspiration injury, all animals developed evidence of severe lung injury characterized by a significant decrease in mean Crs to a value of less than $50 \%$ of its baseline and by a dramatic drop in mean $\mathrm{PaO}_{2}$ to a level less than $80 \mathrm{~mm} \mathrm{Hg}$ [10.7 kPa] (Table 1). Additionally, a significant decrease in mean arterial $\mathrm{pH}$ and significant increases in $\mathrm{PaCO}_{2}$, alveolar-arterial oxygen gradient $\left(\mathrm{A}-\mathrm{aDO}_{2}\right)$, and peak inspiratory pressure after meconium instillation were noted (Table 1). All study animals survived until the end of experiments.

Effects of surfactant lavage. During the lavage procedure, we observed brief oxygenation desaturation. The $\mathrm{SpO}_{2}$ went down from $90-95$ to $70-75 \%$ in all three lavage groups and returned back to higher than $80 \%$ in $\sim 1 \mathrm{~min}$, and then continuously went up to higher than $90 \%$ after one additional min. Tachycardia and occasional bradycardia with mild changes in blood pressures were seen in some animals. After $\mathrm{SpO}_{2}$ recovered, the heart rate and blood pressure were stable until the end of the experiments in the three lavage groups. The time needed to accomplish the total lavage procedures (two aliquots) was 7-8 min. Most of the fluid lavaged from the lungs showed a dark bloody and/or greenish appearance. The ratio of fluid suctioned out of the lungs after BAL was significantly different among the groups $(p<0.05)$, and it was highest in the lavage-30 group (56 $\pm 1 \%$ ) compared with the other two lavage groups $(39 \pm 4 \%$ and $40 \pm 3 \%$ in lavage- 10 and lavage-20 groups, respectively). Thus, the fluid deposition in the lungs was $\sim 44 \%$ in lavage- 30 group and $60 \%$ in the other two groups.

The serial changes in cardiopulmonary profiles during the 4-h observation period are tabulated in Fig. 1. As shown, mean values of $\mathrm{PaO}_{2}$ in the control group remained at lower than 100 $\mathrm{mm} \mathrm{Hg}$ for the entire 4-h observation period. The $\mathrm{PaO}_{2}$ of the lavage-10 group improved 90 min after lavage and remained at a level around $100 \mathrm{~mm} \mathrm{Hg}$ until the end of the experiments. In contrast, $\mathrm{PaO}_{2}$ in the lavage- 20 and lavage- 30 groups displayed a trend toward improvement over time, and they were significantly different from the control and lavage-10 groups $(p<0.05)$ (Fig. 1A). The changes in $\mathrm{A}-\mathrm{aDO}_{2}$ also revealed significantly lower values in the lavage- 20 and lavage- 30 groups than the control and lavage-10 groups $(p<0.05)$ (Fig. $1 B$ ). We also found a tendency of higher $\mathrm{PaCO}_{2}$ and lower $\mathrm{pH}$ in the control group than the other three treatment groups during the last hour of the experiment; however, there was no significant difference in $\mathrm{PaCO}_{2}$ and $\mathrm{pH}$ among all study groups over time (Fig. $1 C$ and $D$ ). The changes in heart rate and MBP had a relatively unstable trend in the control group, but there was no significant difference among the four study groups during the 4-h observation period (Fig. $1 E$ and $F$ ). Additionally, significantly better Crs was noted in the lavage-20 and lavage-30 groups than in the control and lavage-10 groups $(p<0.05)$ (Fig. 1G).

Pathologic findings. The gross appearance of the lungs of the control group seemed with multiple focal meconium impactions, atelectasis, and focal hemorrhage, and those were much less seen in all three lavage groups. The light microscopic assessments of lung tissue found marked hemorrhage,

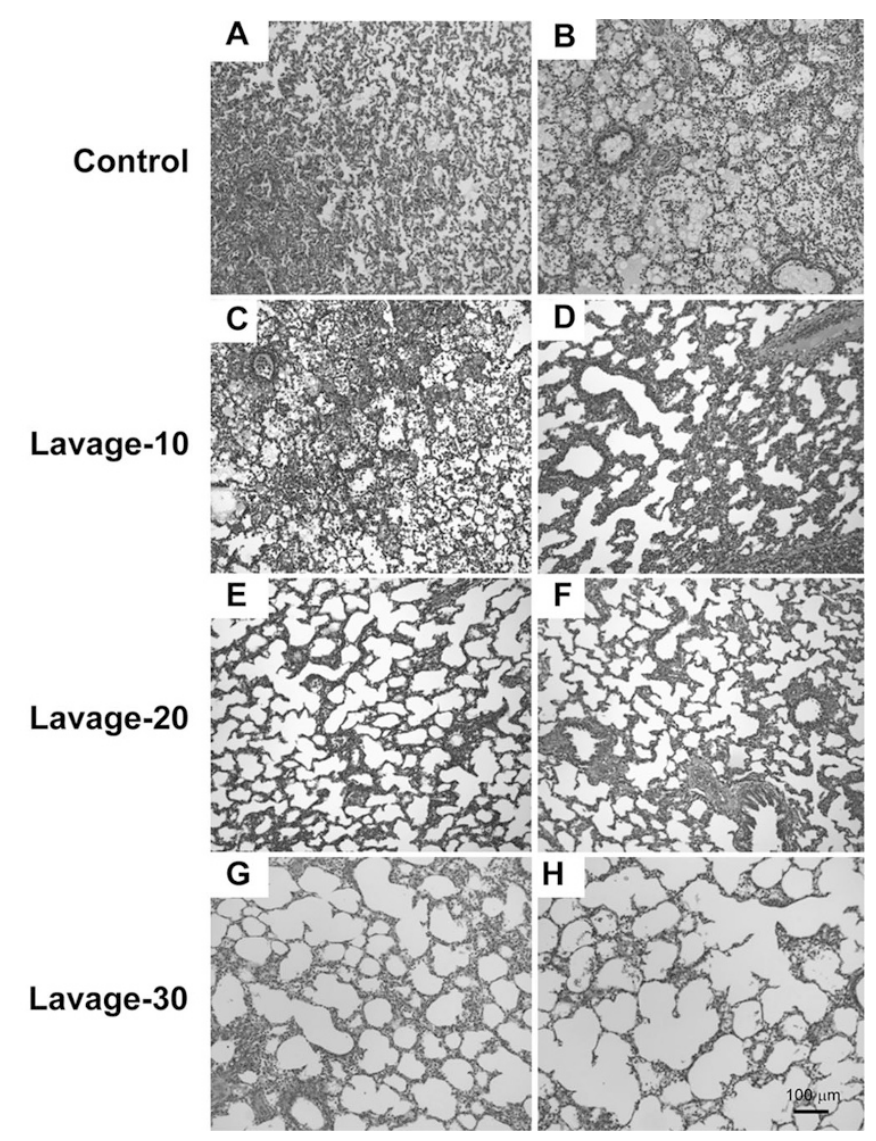

Figure 2. Representative pulmonary histologic pictures in dependent $(A, C$, $E$, and $G$ ) and nondependent $(B, D, F$, and $H$ ) sites of four study groups (stained with hematoxylin and eosin). Significant hemorrhage, atelectasis, and inflammatory infiltrations are present in control and lavage-10 groups, especially at the dependent sites, and much less in the other two groups. Original magnification $\times 100$, bar: $100 \mu \mathrm{m}$.

atelectasis, and inflammatory infiltrations in lung specimens of the control and lavage-10 groups (Fig. 2). In contrast, these pathologic injuries were markedly alleviated in lung specimens of the lavage-20 and lavage-30 groups (Fig. 2). The semiquantitative lung injury scores of the dependent and nondependent sites are shown in Table 4. As shown, the total lung injury scores of dependent sites in the lavage- 20 and lavage-30 groups were significantly lower than those in the control and lavage-10 groups, but there was no significant difference between lavage-20 and lavage-30 groups.

\section{DISCUSSION}

Our study demonstrated significantly better lung function in meconium-injured animals receiving 20 or $30 \mathrm{~mL} / \mathrm{kg}$ diluted surfactant lavage than those receiving $10 \mathrm{~mL} / \mathrm{kg}$ or no lavage. Therefore, our study supports the hypothesis that using diluted surfactant with an effective lavage volume $(20$ or $30 \mathrm{~mL} / \mathrm{kg}$ in two aliquots) improves the pathophysiological outcome of MAS.

Although various reports have shown some merits in surfactant-lavaged animals than saline-lavaged or nonlavaged animals $(23,25-27,30,32-35)$, it is still not conclusive in the therapeutic techniques. This study focused on comparing the effects of different lavage volumes separated in two aliquots and suggested the use of a relative large lavage volume 
Table 4. Lung injury scores of study groups

\begin{tabular}{|c|c|c|c|c|c|c|c|}
\hline & $\begin{array}{c}\text { Alveolar } \\
\text { inflammation }\end{array}$ & $\begin{array}{c}\text { Interstitial } \\
\text { inflammation }\end{array}$ & $\begin{array}{c}\text { Alveolar } \\
\text { hemorrhage }\end{array}$ & $\begin{array}{c}\text { Interstitial } \\
\text { hemorrhage }\end{array}$ & Atelectasis & Necrosis & $\begin{array}{c}\text { Total } \\
\text { scores }\end{array}$ \\
\hline \multicolumn{8}{|l|}{ Dependent site } \\
\hline Control & $1.5(0-4)$ & $3(2-4)$ & $2(0-4)$ & $2(1-2)$ & $3(2-4)$ & $1.5(1-2)$ & $13(9-17)$ \\
\hline Lavage-10 & $1(0-2)$ & $3(2-3)$ & $0(0-2)$ & $1(0-1)$ & $3(3-3)$ & $1(1-2)$ & $9(8-11)^{*}$ \\
\hline Lavage-20 & $1(0-2)$ & $2(2-3)$ & $0(0-1)$ & $0(0-1)$ & $2(0-3)$ & $1(1-2)$ & $6(5-9)^{* \dagger}$ \\
\hline Lavage-30 & $1(0-1)$ & $2(1-2)$ & $0(0-1)$ & $0(0-1)$ & $2(1-2)$ & $1(1-2)$ & $5.5(5-7)^{* \dagger}$ \\
\hline \multicolumn{8}{|c|}{ Nondependent site } \\
\hline Control & $0.5(0-3)$ & $2(2-3)$ & $1.5(0-4)$ & $2(0-3)$ & $2(0-3)$ & $1(0-2)$ & $9.5(5-16)$ \\
\hline Lavage-10 & $0(0-1)$ & $2(2-3)$ & $0(0-1)$ & $0(0-1)$ & $2(0-3)$ & $1(1-1)$ & $6(3-7) \div$ \\
\hline Lavage-20 & $0(0-0)$ & $2.5(2-3)$ & $0(0-1)$ & $0(0-1)$ & $1(0-3)$ & $1(1-1)$ & $5(4-9)$ \\
\hline Lavage-30 & $0(0-0)$ & $1(1-3)$ & $0(0-0)$ & $0(0-1)$ & $0.5(0-2)$ & $1(0-1)$ & $3.5(1-6) \neq$ \\
\hline
\end{tabular}

$* p<0.05 v s$. control group of the same site.

$\dagger p<0.05$ vs. Lavage-10 group of the same site.

$\ddagger p<0.05 v s$. dependent site of the same group. Data are expressed as the median (range).

$(20-30 \mathrm{~mL} / \mathrm{kg}$ ) in treating MAS. Reasonable explanations include effectively removing aspirated meconium by using enough lavage volume and evenly replacing the dysfunctional endogenous surfactant with the exogenous diluted surfactant.

Although small lavage volume may have fewer adverse events than large volume use (36), too many aliquots may have a prolonged lavage time and oxygenation desaturation. The reports of Dargaville et al. $(29,31)$ and we had previously demonstrated that only brief oxygenation desaturation would be found while using a relative large volume $(15 \mathrm{~mL} / \mathrm{kg})$ and a quick return of oxygenation saturation could be seen soon after the lavage procedure with no sustained adverse effects. That is also a constant finding in this study. The use of only two aliquots with an effective lavage volume did effectively remove the meconium debris and minimize the frequency and duration of oxygenation desaturation. The presented animal experiments demonstrated that using either 20 or $30 \mathrm{~mL} / \mathrm{kg}$ diluted surfactant in two aliquots to perform BAL was safe, effective, and time-saving; so, sick neonates with MAS may tolerate the lavage procedure and have no sustained physiologic instability.

The latest clinical, multicenter and multicountry clinical trial executed by Dargaville et al. (43) evaluated the effects of BAL with two aliquots of $15 \mathrm{~mL} / \mathrm{kg}$ diluted surfactant in critical neonates with MAS. Although the volume of 15 $\mathrm{mL} / \mathrm{kg}$ is close to the theoretical functional residual capacity of a normal neonatal lung, it should be much smaller in a meconium-injured and atelectatic lung. Lavage fluid overflow during instillation was frequently observed while using 15 $\mathrm{mL} / \mathrm{kg}$ in each aliquot to perform BAL in our neonatal patients and animal experiments (31). In addition, exogenous surfactant is an expensive medical product, and this study demonstrated a BAL volume of $20 \mathrm{~mL} / \mathrm{kg}$ was as effective as 30 $\mathrm{mL} / \mathrm{kg}$ so one third of the surfactant dose can be saved. That means one vial of Survanta can be saved in a full-term or over-term neonate. We suggest for consideration using a lavage volume of $20 \mathrm{~mL} / \mathrm{kg}$ in two aliquots (somewhat less than theoretically functional residual capacity) to perform therapeutic BAL in MAS because the cases may not only have a better lung function, but also be shorten the procedure duration and reduced the expense.
The ventilators used in this study were conventional mechanical ventilators. In neonates, some serious cases may also suffer from persistent pulmonary hypertension of the newborn. Inhaled nitric oxide and high-frequency oscillatory or jet ventilation have been reported to be used successfully in combination with therapeutic surfactant lavage $(29,31,37,38)$. Therefore, combination therapies of advanced ventilatory cares and surfactant lavage are acceptable and may have synergetic effects in clinical application.

Nevertheless, this study only focused on the pathophysiological responses in newborn piglets with MAS so the changes on the pulmonary arterial pressure and the brain tissue perfusion during the lavage period are still questionable. In addition, other limitations of this study included meconium recovery was not measured, observation period was only $4 \mathrm{~h}$, and some other possible influencing factors were not investigated. Dargaville et al. (44) had demonstrated that open suction, vibratory chest squeezing, and an aliquot volume of $15 \mathrm{~mL} / \mathrm{kg}$ may improve the meconium recovery and the efficacy of BAL. In our study, the lavage fluid recovery of lavage-30 was higher than lavage- 20 group ( $\sim 56$ vs. $40 \%$ of instilled fluid, respectively) so the meconium recovery may be higher in lavage-30 than lavage- 20 group. Such that using $30 \mathrm{~mL} / \mathrm{kg}$ of diluted surfactant is possible to have a more sustained benefit than 20 $\mathrm{mL} / \mathrm{kg}$. Therefore, further studies to elucidate these doubts will be necessary for future human applications.

In conclusion, using $20 \mathrm{~mL} / \mathrm{kg}$ diluted surfactant in two aliquots to perform therapeutic BAL was as effective as 30 $\mathrm{mL} / \mathrm{kg}$ in improving the short-term pathophysiological outcomes in MAS and may have some possible benefits of reduced price and complications. Thus, therapeutic BAL with 20 or $30 \mathrm{~mL} / \mathrm{kg}$ diluted surfactant in two aliquots is an effective and promising technique to treat MAS and that may warrant consideration clinically in treating MAS.

Acknowledgments. The authors thank the advisement in the lavage techniques from Dr. Peter A. Dargaville and Beverley Copnell at the Murdoch Children's Research Institute and Royal Children's hospital, Melbourne, Australia. They also thank the expert statistical help from Benjamin Ing-Tiau Kuo, M.D., Ph.D., at Taipei Veterans General Hospital, and the 
technical help from Miss Jui-Yu Lin and Miss Shr-Yun Chiou at National Yang-Ming University, Taipei, Taiwan.

\section{REFERENCES}

1. Ford JW 2006 Neonatal ECMO: current controversies and trends. Neonatal Netw 25:229-238

2. Dargaville PA, Copnell B; Australian and New Zealand Neonatal Network 2006 The epidemiology of meconium aspiration syndrome: incidence, risk factors, therapies, and outcome. Pediatrics 117:1712-1721

3. Lin HC, Su BH, Lin TW, Tsai CH, Yeh TF 2005 System-based strategy for the management of meconium aspiration syndrome: 198 consecutive cases observations. Acta Paediatr Taiwan 46:67-71

4. Bae CW, Takahashi A, Chida S, Sasaki M 1998 Morphology and function of pulmonary surfactant inhibited by meconium. Pediatr Res 44:187-191

5. Cleary GM, Antunes MJ, Ciesielka DA, Higgins ST, Spitzer AR, Chander A 1997 Exudative lung injury is associated with decreased levels of surfactant proteins in a rat model of meconium aspiration. Pediatrics 100:998-1003

6. Sun B, Curstedt T, Robertson B 1993 Surfactant inhibition in experimental meconium aspiration. Acta Paediatr 82:182-189

7. Moses D, Holm BA, Spitale P, Liu M, Enhorning G 1991 Inhibition of pulmonary surfactant function by meconium. Am J Obstet Gynecol 164:477-481

8. Ogawa Y, Shimizu H, Itakura Y, Ohama Y, Arakawa H, Amizuka T, Obata M, Kakinuma R 1999 Functional pulmonary surfactant deficiency and neonatal respiratory disorders. Pediatr Pulmonol Suppl 18:175-177

9. Fox WW, Gewitz MH, Dinwiddie R, Drummond WH, Peckham GJ 1977 Pulmonary hypertension in the perinatal aspiration syndrome. Pediatrics 59:205-211

10. Perlman EJ, Moore GW, Hutchins GM 1989 The pulmonary vasculature in meconium aspiration. Hum Pathol 20:701-706

11. El Shahed AI, Dargaville P, Ohlsson A, Soll RF 2007 Surfactant for meconium aspiration syndrome in full term/near term infants. Cochrane Database Syst Rev 3:CD002054

12. Dargaville PA, Mills JF 2005 Surfactant therapy for meconium aspiration syndrome: current status. Drugs 65:2569-2591

13. Ogawa Y, Shimizu H 2000 Current strategy for management of meconium aspiration syndrome. Acta Paediatr Taiwan 41:241-245

14. Engle WA; American Academy of Pediatrics Committee on Fetus and Newborn 2008 Surfactant-replacement therapy for respiratory distress in the preterm and term neonate. Pediatrics 121:419-432

15. Colvero MO, Fiori HH, Fiori RM, Luz JH, de Paula D, Oppermann C, Pitrez PM, da Silva VD, Colvero AP 2008 Bronchoalveolar lavage plus surfactant in a piglet model of meconium aspiration syndrome. Neonatology 93:188-192

16. Rosegger H, Engele H, Haas J 1987 Tracheobronchial lavage- a supplementary measure in the initial management of meconium aspiration syndrome. Wien Klin Wochenschr 99:843-847

17. Möller JC, Kohl M, Reiss I, Wiebke D, Nitsche EM, Göpel W, Gortner L 1999 Saline lavage with substitution of bovine surfactant in term neonates with meconium aspiration syndrome (MAS) transferred for extracorporeal membrane oxygenation (ECMO): a pilot study. Crit Care 3:19-22

18. Ibara S, Ikenoue T, Murata Y, Sakamoto H, Saito T, Nakamura Y, Asano H, Hirano T, Kuraya K, Maruyama H 1995 Management of meconium aspiration syndrome by tracheobronchial lavage and replacement of surfactant-TA. Acta Paediatr Jpn 37:64-67

19. Mosca F, Colnaghi M, Castoldi F 1996 Lung lavage with a saline volume similar to functional residual capacity followed by surfactant administration in newborns with severe meconium aspiration syndrome. Intensive Care Med 22:1412-1413

20. Lachmann B, Robertson B, Petro W, Eichhorn K, Seidel M, Winsel K, Kunze D, Vogel J 1976 Experimental respiratory distress induced by removal of alveolar surfactant with bronchial lavage. Bull Eur Physiopathol Respir 12:186-187

21. Meister J, Balaraman V, Ramirez M, Uyehara CF, Killeen J, Ku T, Person D, Easa D 2004 Lavage administration of dilute surfactant in a piglet model of meconium aspiration. Lung 182:227-240

22. Balaraman V, Meister J, Ku TL, Sood SL, Tam E, Killeen J, Uyehara CF, Egan E, Easa D 1998 Lavage administration of dilute surfactants after acute lung injury in neonatal piglets. Am J Respir Crit Care Med 158:12-17
23. Calkovska A, Mokra D, Drgova A, Zila I, Javorka K 2008 Bronchoalveolar lavage with pulmonary surfactant/dextran mixture improves meconium clearance and lung functions in experimental meconium aspiration syndrome. Eur J Pediatr 167:851857

24. Wiswell TE, Knight GR, Finer NN, Donn SM, Desai H, Walsh WF, Sekar KC, Bernstein G, Keszler M, Visser VE, Merritt TA, Mannino FL, Mastrioianni L, Marcy B, Revak SD, Tsai H, Cochrane CG 2002 A multicenter, randomized, controlled trial comparing Surfaxin (Lucinactant) lavage with standard care for treatment of meconium aspiration syndrome. Pediatrics 109:1081-1087

25. Jeng MJ, Soong WJ, Lee YS, Chang HL, Shen CM, Wang CH, Yang SS, Hwang B 2006 Effects of therapeutic bronchoalveolar lavage and partial liquid ventilation on meconium-aspirated newborn piglets. Crit Care Med 34:1099-1105

26. Paranka MS, Walsh WF, Stancombe BB 1992 Surfactant lavage in a piglet model of meconium aspiration syndrome. Pediatr Res 31:625-628

27. Ohama Y, Yunosuke O 1999 Treatment of meconium aspiration syndrome with surfactant lavage in an experimental rabbit model. Pediatr Pulmonol 28:18-23

28. Lam BC, Yeung CY 1999 Surfactant lavage for meconium aspiration: a pilot study. Pediatrics 103:1014-1018

29. Dargaville PA, Mills JF, Copnell B, Loughnan PM, McDougall PN, Morley CJ 2007 Therapeutic lung lavage in meconium aspiration syndrome: a preliminary report. J Paediatr Child Health 43:539-545

30. Dargaville PA, Mills JF, Headley BM, Chan Y, Coleman L, Loughnan PM, Morley CJ 2003 Therapeutic lung lavage in the piglet model of meconium aspiration syndrome. Am J Respir Crit Care Med 168:456-463

31. Lo CW, Jeng MJ, Chang FY, Yang JF, Lee YS, Soong WJ, Chen SJ, Tang RB 2008 Therapeutic lung lavage with diluted surfactant in neonates with severe meconium aspiration syndrome. J Chin Med Assoc 71:103-109

32. Zhang E, Hiroma T, Sahashi T, Taki A, Yoda T, Nakamura T 2005 Airway lavage with exogenous surfactant in an animal model of meconium aspiration syndrome. Pediatr Int 47:237-241

33. Schlösser RL, Veldman A, Fischer D, Funk B, Brand J, von Loewenich V 2002 Comparison of effects of perflubron and surfactant lung lavage on pulmonary gas exchange in a Piglet Model of Meconium Aspiration. Biol Neonate 81:126-131

34. Nakamura T, Matsuzawa S, Sugiura M, Tamura M 2000 A randomised control study of partial liquid ventilation after airway lavage with exogenous surfactant in a meconium aspiration syndrome animal model. Arch Dis Child Fetal Neonatal Ed 82:F160-F162

35. Ohama Y, Itakura Y, Koyama N, Eguchi H, Ogawa Y 1994 Effect of surfactant lavage in a rabbit model of meconium aspiration syndrome. Acta Paediatr Jpn $36: 236-238$

36. Hung HY, Jim WT, Hsu CH, Chang JH, Peng CC, Shih SL, Chang HY, Kao HA 2006 Small versus large volume dilute surfactant lavage for meconium aspiration syndrome. Acta Paediatr Taiwan 47:181-186

37. Lista G, Bianchi S, Castoldi F, Fontana P, Cavigioli F 2006 Bronchoalveolar lavage with diluted porcine surfactant in mechanically ventilated term infants with meconium aspiration syndrome. Clin Drug Investig 26:13-19

38. Lejeune T, Pfister RE 2005 Surfactant lavage for extracorporeal membrane oxygenation-requiring meconium aspiration syndrome-a cheap alternative. Eur J Pediatr 164:331-333

39. Salvia-Roigés MD, Carbonell-Estrany X, Figueras-Aloy J, Rodríguez-Miguélez JM 2004 Efficacy of three treatment schedules in severe meconium aspiration syndrome. Acta Paediatr 93:60-65

40. Cochrane CG, Revak SD, Merritt TA, Schraufstätter IU, Hoch RC, Henderson C, Andersson S, Takamori H, Oades ZG 1998 Bronchoalveolar lavage with KL4surfactant in models of meconium aspiration syndrome. Pediatr Res 44:705-715

41. Rotta AT, Steinhorn DM 1998 Partial liquid ventilation reduces pulmonary neutrophil accumulation in an experimental model of systemic endotoxemia and acute lung injury. Crit Care Med 26:1707-1715

42. Jeng MJ, Kou YR, Sheu CC, Hwang B 2003 Effects of exogenous surfactant supplementation and partial liquid ventilation on acute lung injury induced by wood smoke inhalation in newborn piglets. Crit Care Med 31:1166-1174

43. Dargaville PA, Copnell B Controlled trial of therapeutic lung lavage in meconium aspiration syndrome (the lessMAS trial). Available at: http://www.rch.org.au/ neonatal_rch/research.cfm?doc_id=6953. Accessed May 15, 2008

44. Dargaville PA, Copnell B, Tingay DG, Gordon MJ, Mills JF, Morley CJ 2008 Refining the method of therapeutic lung lavage in meconium aspiration syndrome. Neonatology 94:160-163 